\title{
Affordable Development and Demonstration of a Small NTR Engine and Stage: How Small is Big Enough? \\ (AIAA-2015-4524)
}

\section{EXPL-06 Nuclear Propulsion}

\author{
S. K. Borowski and R. J. Sefcik (NASA GRC) \\ J. E. Fittje and D. R. McCurdy (Vantage Partners, LLC@GRC) \\ A. L. Qualls and B. G. Schnitzler (ORNL) \\ J. Werner (INL) and A. Weitzberg (DOE Consultant) \\ C. R. Joyner (Aerojet Rocketdyne) \\ 216-977-7091, Stanley.K.Borowski@nasa.gov
}

presented at

AIAA Space \& Astronautics Forum \& Exposition (Space 2015)

Pasadena, CA

Tuesday, September 1, 2015

Glenn Research Center 


\section{Overview of NTP Development Activities by NASA and DOE}

- In FY11, NASA formulated a plan for Nuclear Thermal Propulsion (NTP) development that included "Foundational Technology Development" followed by system-level "Technology Demonstrations"

- The ongoing NTP project, funded by NASA's Advanced Exploration Systems (AES) program, is focused on Foundational Technology Development and includes 5 key task activities:

(1) Fuel element fabrication and non-nuclear validation testing of "heritage" fuel options;

(2) Engine conceptual design;

(3) Mission analysis and engine requirements definition;

(4) Identification of affordable options for ground testing; and

(5) Formulation of an affordable and sustainable NTP development program

- Performance parameters for "Point of Departure" designs for a small "criticality-limited" and full size $25 \mathrm{klb}_{\mathrm{f}}$-class engine were developed during FY's 13-14 using heritage fuel element designs for both Rover/NERVA Graphite Composite (GC) and Ceramic Metal (Cermet) fuel forms

- To focus the fuel development effort and maximize use of its resources, the AES program decided, in FY14, that a "leader-follower" down selection between GC and cermet fuel was required

- An Independent Review Panel (IRP) was convened by NASA and tasked with reviewing the available fuel data and making a recommendation to NASA. In February 2015, the IRP recommended and the AES program endorsed GC as the leader fuel

- In FY'14, a preliminary development schedule / DDT\&E plan was produced by GRC, DOE \& industry for the AES program. Assumptions, considerations and key task activities are presented here

- Two small ( 7.5 and $16.5 \mathrm{klb}_{f}$ ) engine sizes were considered for ground and flight technology demonstration within a 10-year timeframe; their ability to support future human exploration missions was also examined and a recommendation on a preferred size is provided 


\section{Rover / NERVA Reactor Core Configuration: SNRE Fuel Element / Tie Tube Bundle Arrangement}

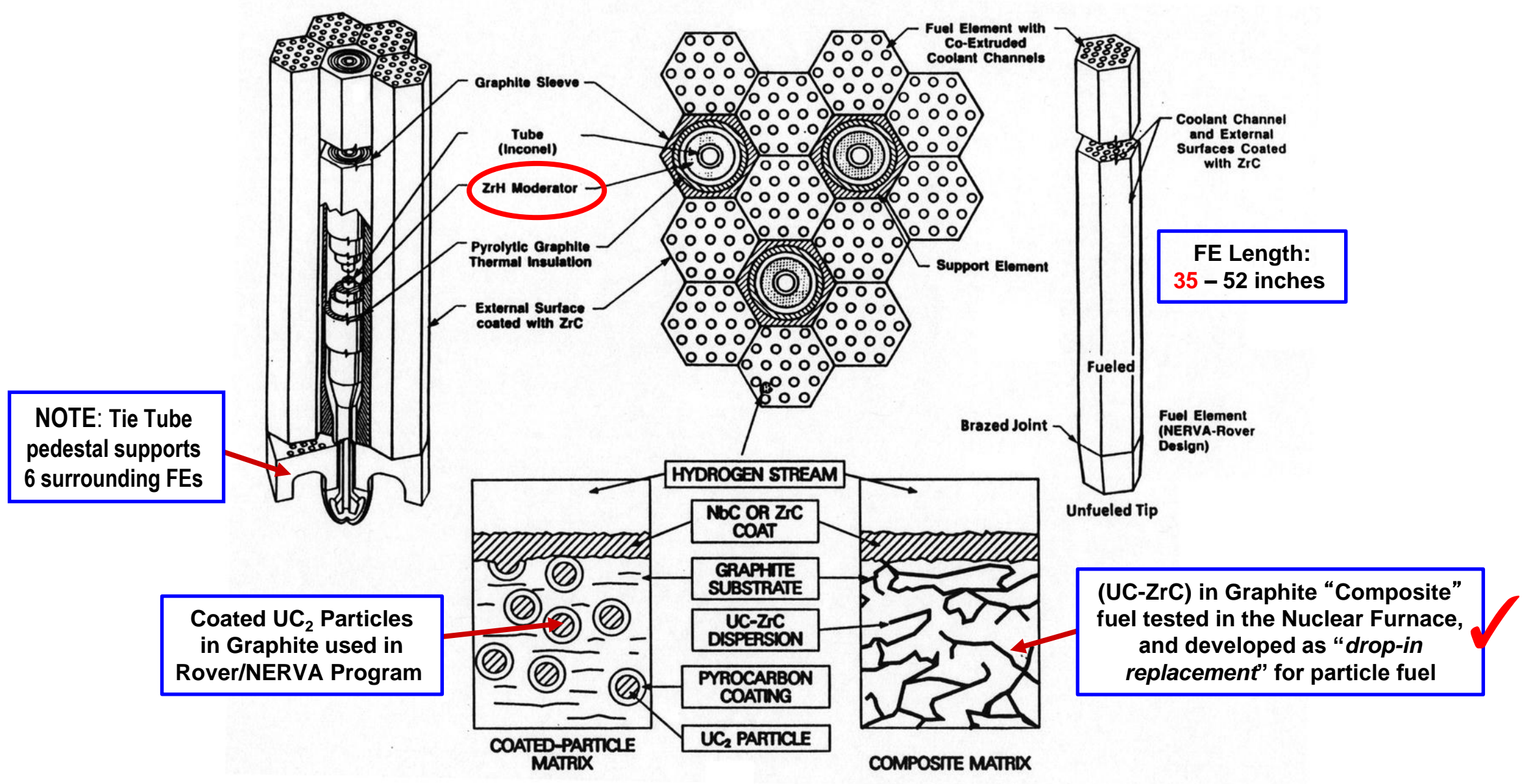




\section{GRC/DOE Integrated Neutronics, Multi-Physics \& Engine Modeling Approach}

"Propelling Us to New Worlds"

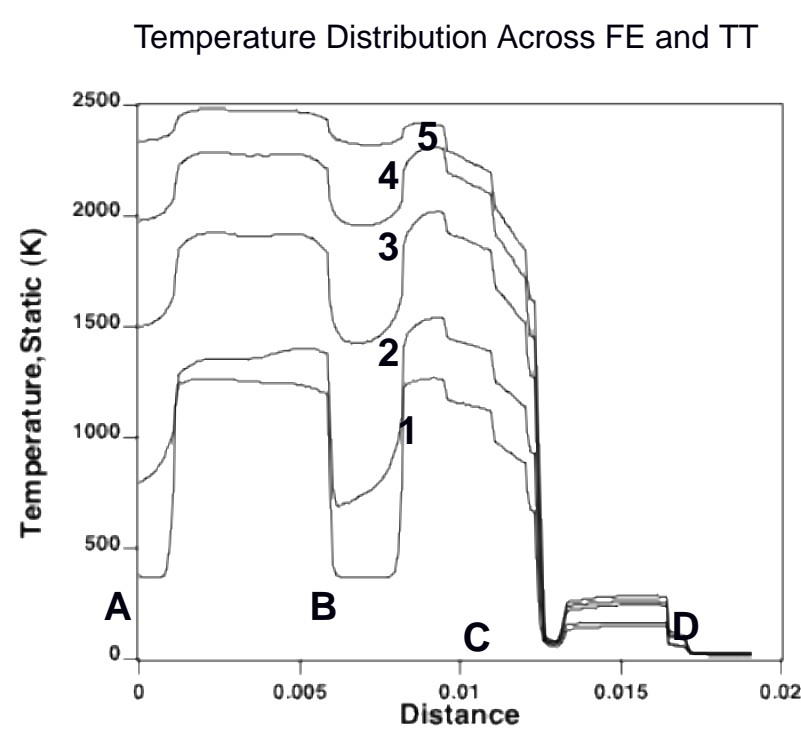

Temperature Distributions at Five Axial Stations

(Numbers Indicate Cold to Hot End Stations)

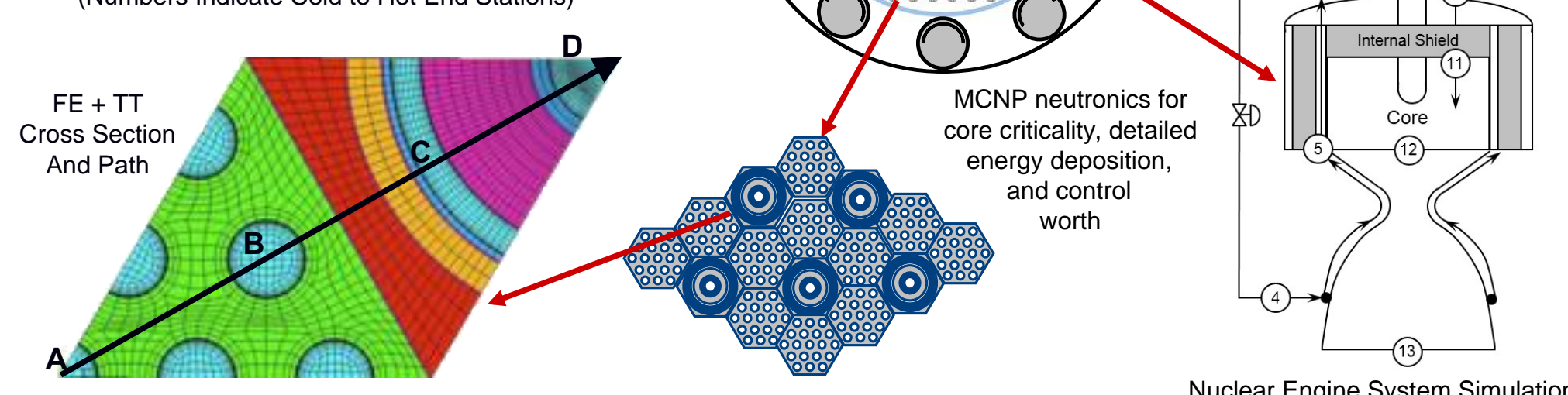

ANSYS Model

Fuel Element-to-Tie Tube ratio varies with engine thrust level

Nuclear Engine System Simulation (NESS) code has been upgraded to use MCNP-generated data 


\section{Fuel Element (FE) - Tie Tube (TT) Arrangements for SNRE-derived Graphite Composite Engines}

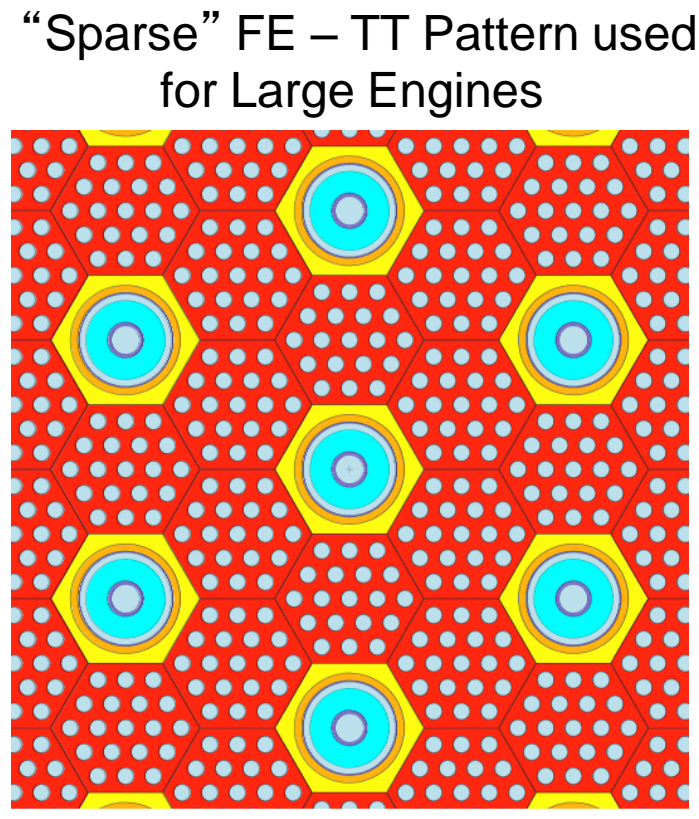

Each FE has 4 adjacent FEs and 2 adjacent TTs with a FE to TT ratio of $\sim 3$ to 1
"SNRE" FE - TT Pattern used in Small Nuclear Rocket Engine

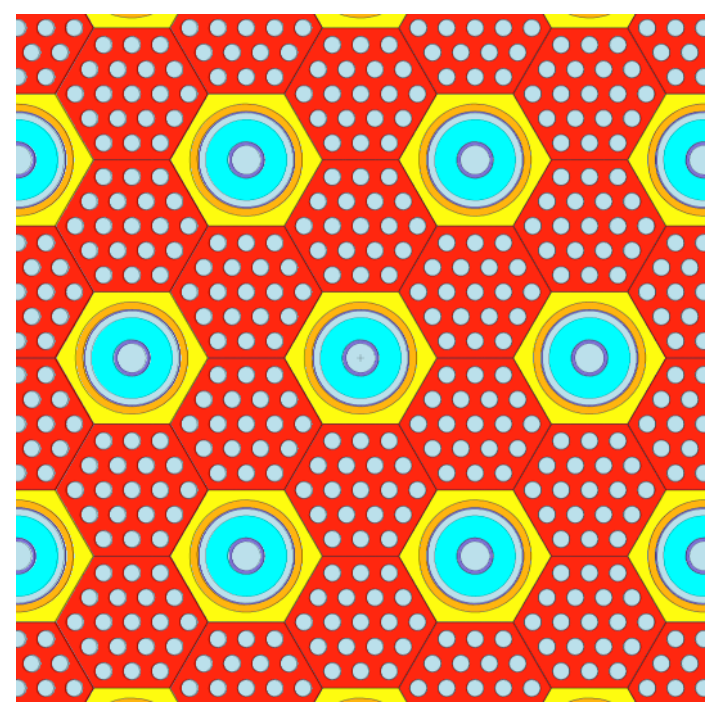

Each FE has 3 adjacent FEs and 3 adjacent TTs with a FE to TT ratio of $\sim 2$ to 1

Used in full-size $25 \mathrm{klb}_{\mathrm{f}}$ Composite Engine Design
"Dense" FE - Tie Tube Pattern used in Lower Thrust Engines

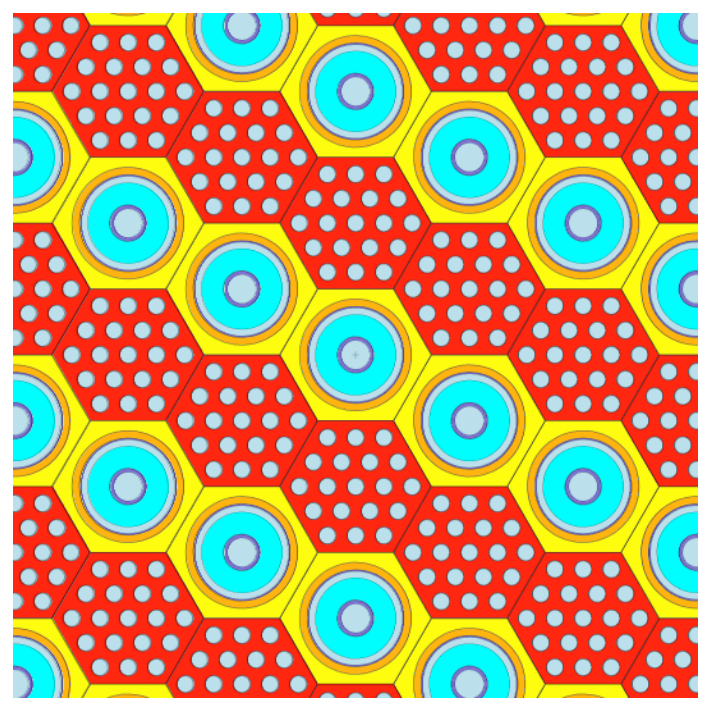

Each FE has 2 adjacent FEs and 4 adjacent TTs with a FE to TT ratio of $\sim 1$ to 1

Used in Small Criticality-Limited Composite Engine Design

NOTE: An important feature common to both the Sparse and SNRE FE - TT patterns is that each tie tube is surrounded by and provides mechanical support for 6 fuel elements 


\section{Performance Characteristics for “Small-to-Full Size" GC SNRE-derived Engines}

Performance Characteristic

Engine System

Thrust $\left(k \mid b_{f}\right)$

Chamber Inlet Temperature (K)

Chamber Pressure (psia)

Nozzle Area Ratio (NAR)

Specific Impulse (s)

Engine Thrust-to-Weight

Approx. Engine Length* $(\mathrm{m})$

Length w/ Retracted Nozzle (m)

\section{Reactor}

Active Fuel Length $(\mathrm{cm})$

Reflector Thickness (cm)

Pressure Vessel Diameter $(\mathrm{cm})$

Element Fuel/Tie Tube Pattern

Type

Number of Fuel Elements

Number of Tie-Tube Elements

Fuel Fissile Loading ( $\mathrm{g} \cup$ per $\mathrm{cm}^{3}$ )

Maximum Enrichment (wt\% U-235)

Maximum Fuel Temperature (K)

Margin to Fuel Melt (K)

$\mathrm{U}-235$ Mass $(\mathrm{kg})$
Small Citicality

Limited Engine

$\hat{L}$

7.52

2739

565

$300: 1$

894

1.91

6.19

4.93

89

14.7

87.7

Dense

260

251

0.60

93

2860

40

27.5
*Varies with thrust level, chamber pressure, NAR and TPA/TVC layout

\section{SNRE}

\section{Baseline}

Baseline +

25 klb $_{f}$ Axial Growth Option

Nominal Enhanced

$\hat{W}$

25.2

2790

1000

$300: 1$

909

$\mathrm{N} / \mathrm{A}$

89

14.7

98.5

SNRE

564

241

0.60

93

2860

40

59.6

$-59.6$
3.42

8.69

6.53

3.06

6.81

3.65

89

14.7

98.5

14.7

98.5

SNRE

564

241

0.25

93

2860

190

36.8
25.1

2940

1000

$300: 1$

945

3.41

8.69

6.53

132

14.7

98.5

SNRE

564

241

0.25

93

3010

40

36.8 


\section{Equipment Assembled at ORNL for Fabrication of Graphite Composite (GC) Fuel Elements}
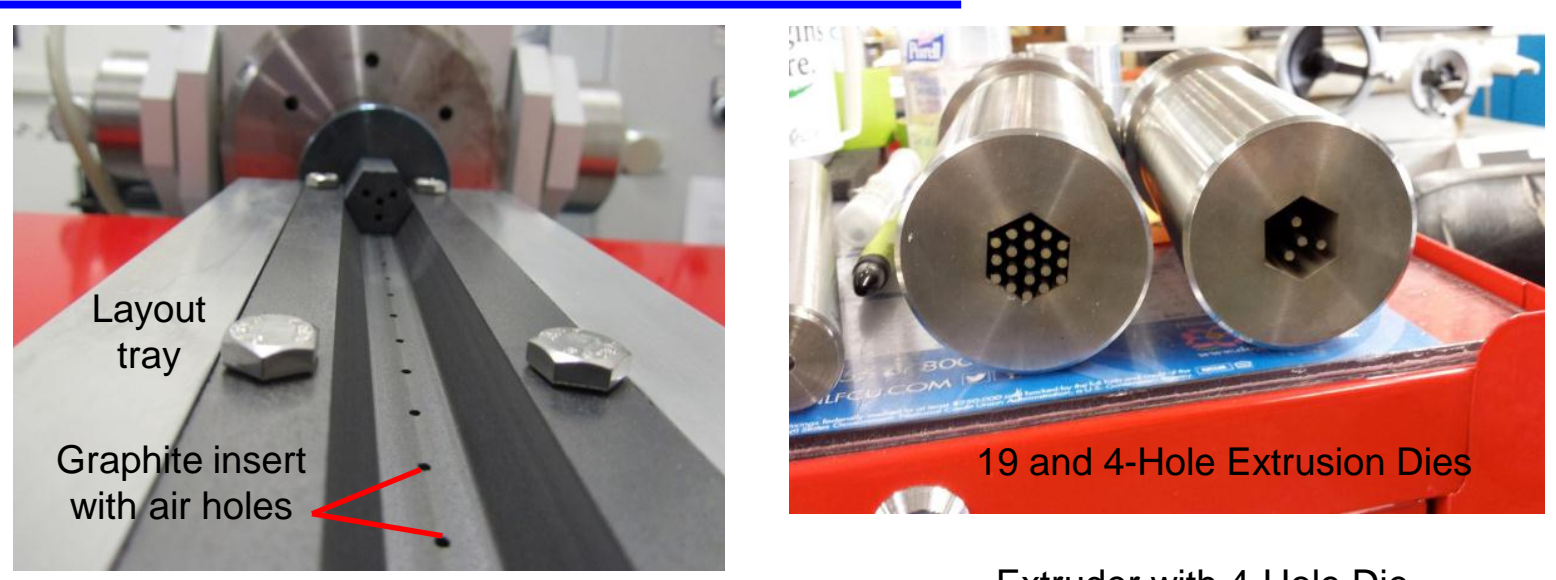

Extruder with 4-Hole Die

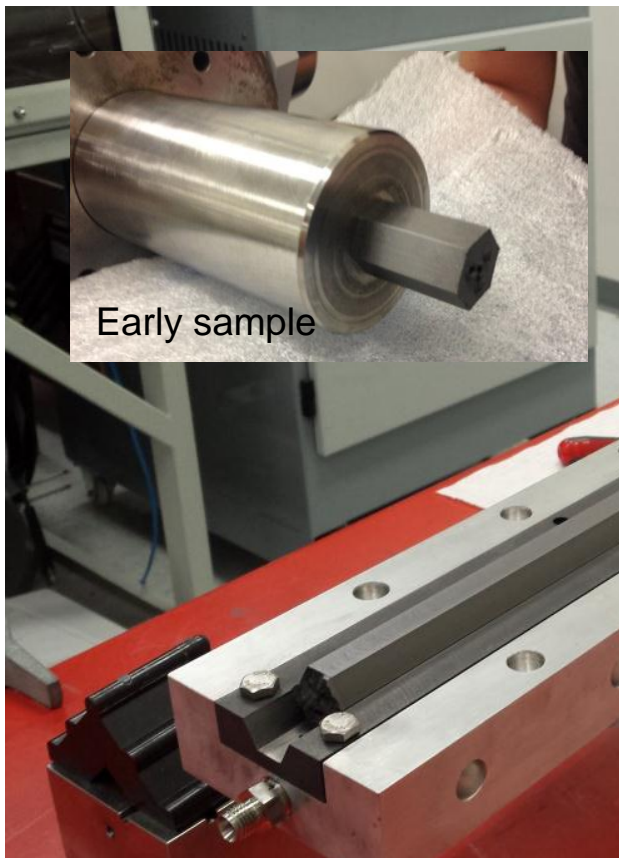

Extral

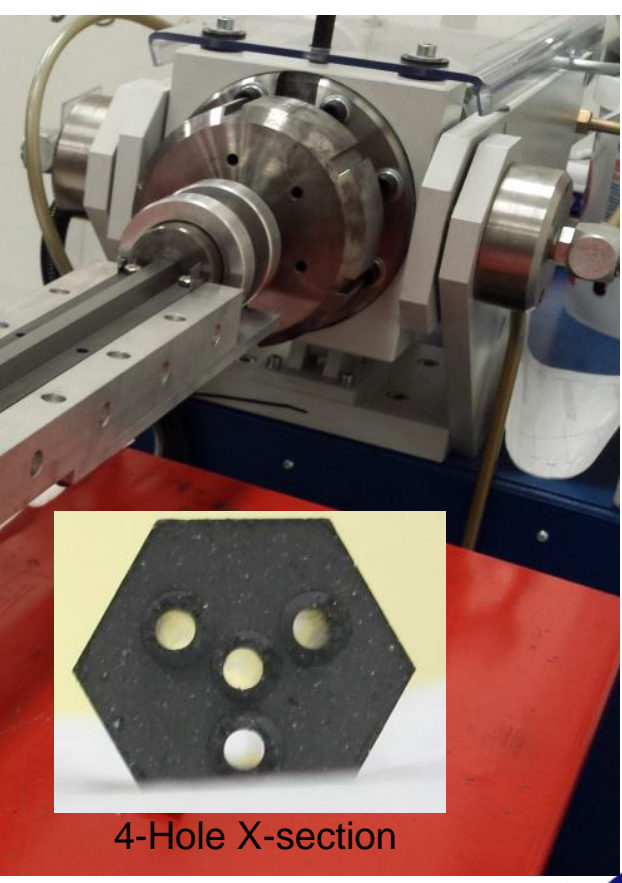

Recent

24 inch

Extrusion
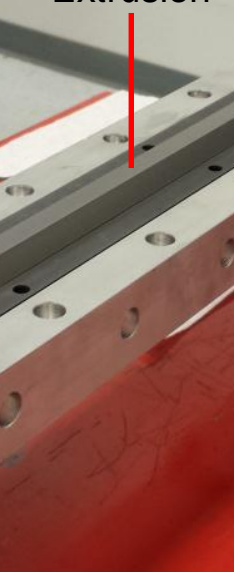

Graphite FE extruder

with installed vent lines for DU capability 


\section{ORNL CVD Furnace for Applying Baseline ZrC Coating along with Alternative Coating Concepts}

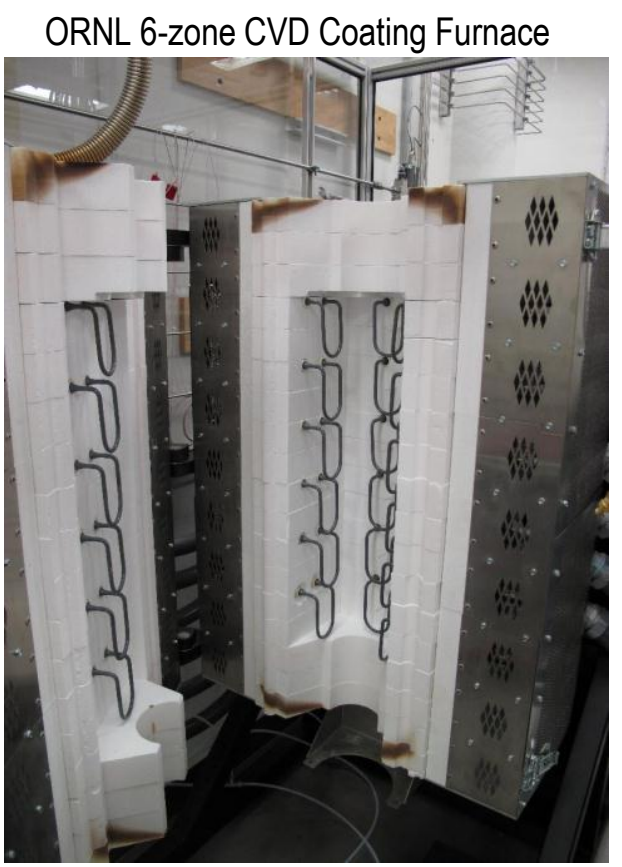

Single Layer ZrC Coating is Baseline

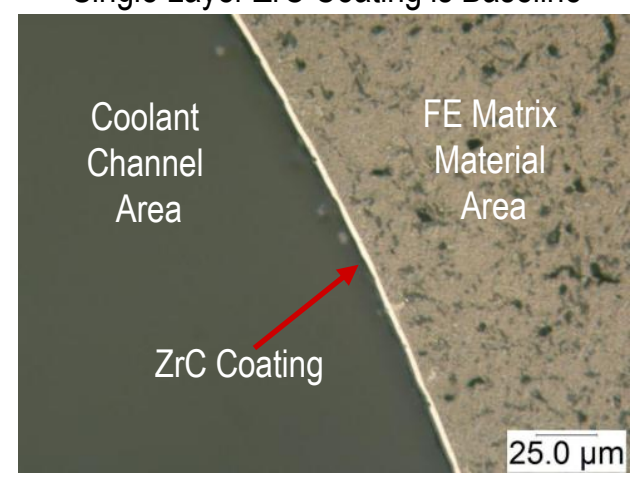

Multilayer Metallic Coating Concept

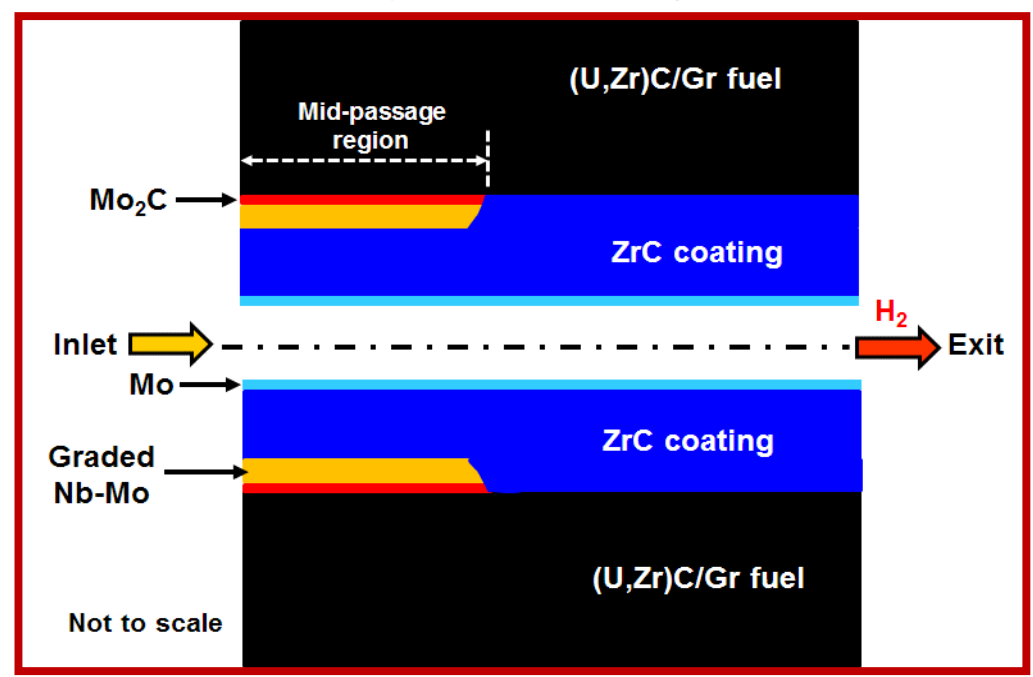

Advantages of Multilayer Coating Approach:

- Minimizes ZrC/(U,Zr)C-graphite matrix CTE differences.

- Ductile compliant metallic layers will accommodate residual stresses.

- Mo overlay seals cracks in the ZrC coating and reduces $\mathrm{H}_{2}$ permeation.

- Mo-Nb layers expected to reduce $\mathrm{H}_{2}$ permeation.

- $\mathrm{Mo}_{2} \mathrm{C}$ expected to be a diffusion barrier for carbon. 


\section{Maximize Use of the NNSS, DAF and Existing Bore Holes / Tunnels}

- Testing should be conducted at the Nevada National Security Site (NNSS) using SAFE (Subsurface Active Filtration of Exhaust) approach in existing boreholes or in long, large diameter horizontal tunnels.

- NNSS provides a large secure, safety zone ( 1375 sq. miles) for conducting NTR testing.

- The Device Assembly Facility (DAF) is located within the NNSS and is available for pre-test staging (assembly and "0-power" critical testing) of engine's reactor system prior to transfer to the borehole or tunnel test location.

- DAF is a collection of interconnected steelreinforced concrete test cells. The entire complex is covered by compacted earth.

- DAF has multiple assembly / test cells; high bays have multi-ton crane capability. The assembly cells are designed to handle SNM.

- Options to use horizontal tunnels exist at the underground U1a complex or the P-tunnel complex located inside the Rainier Mesa.

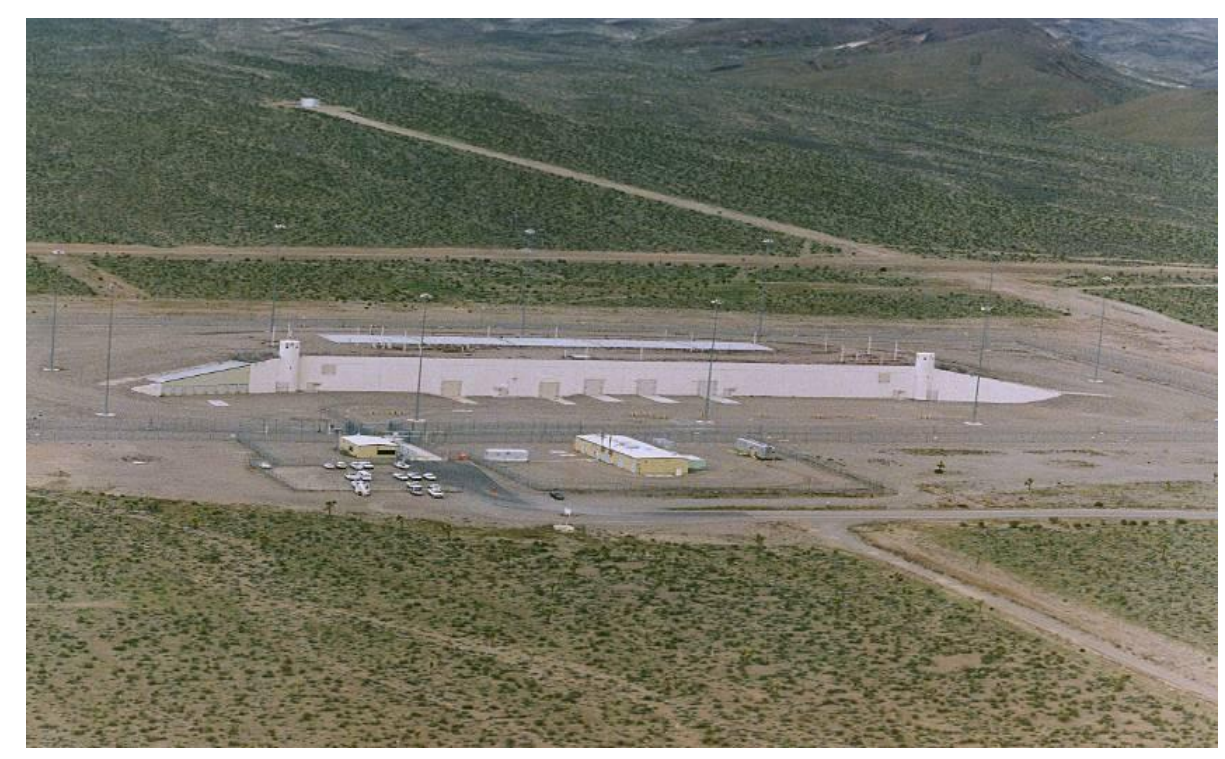

Aerial View of the DAF at the NNSS 


\section{Possible Concepts of Operation for NTP Ground Testing}

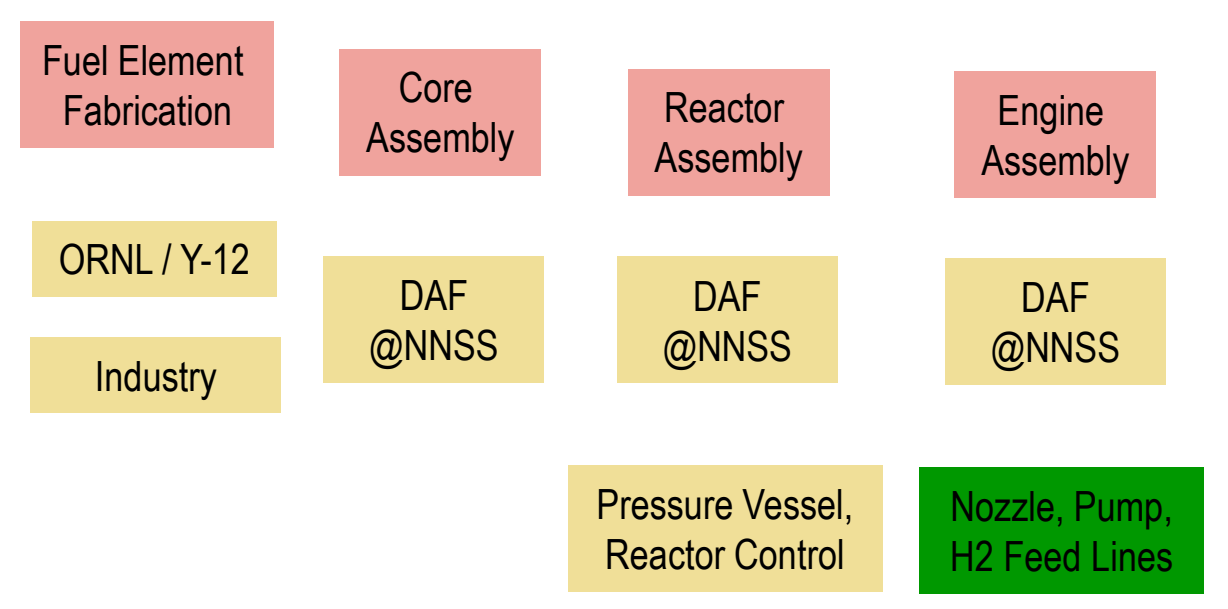

DAF - Device Assembly Facility

PIE - Post Irradiation Examination

NNSS - Nevada National Security Site

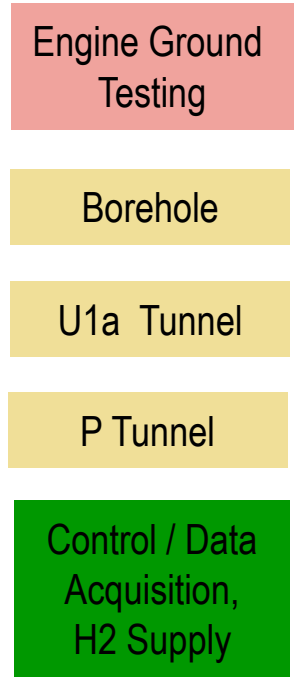

Non-nuclear Components
SHARS " mobile hot cell" unit - funding for development provided by the IAEA

${ }^{*}$ Spent High Activity Radioactive Sources (SHARS)
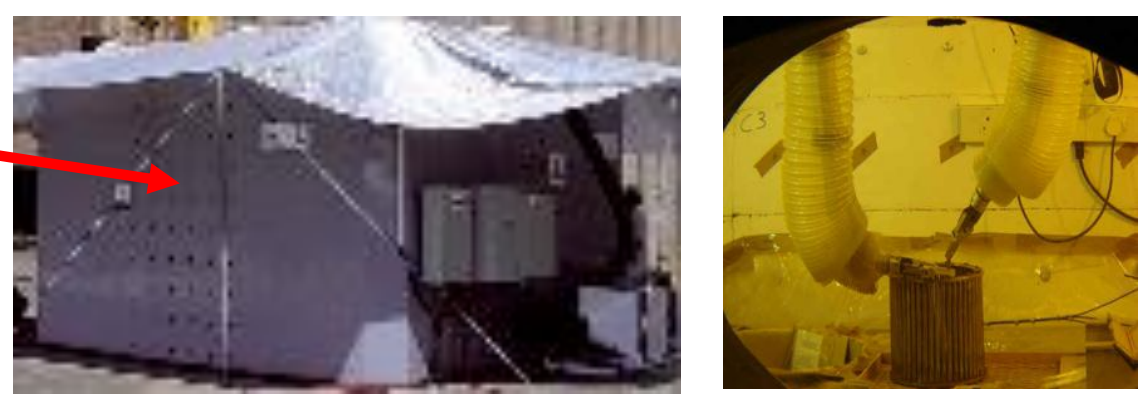

Limited FE and components shipment to INL for PIE

\section{Disassembly and PIE}

FE, components extraction at test site using Portable Hot Cell
Disposal / HEU Recovery

@NNSS entomb in tunnel

@INL following PIE 


\section{Small $7.5 \mathrm{klb}_{\mathrm{f}}$ NTP Engine and Stage for 2025 Lunar Flyby FTD Mission}

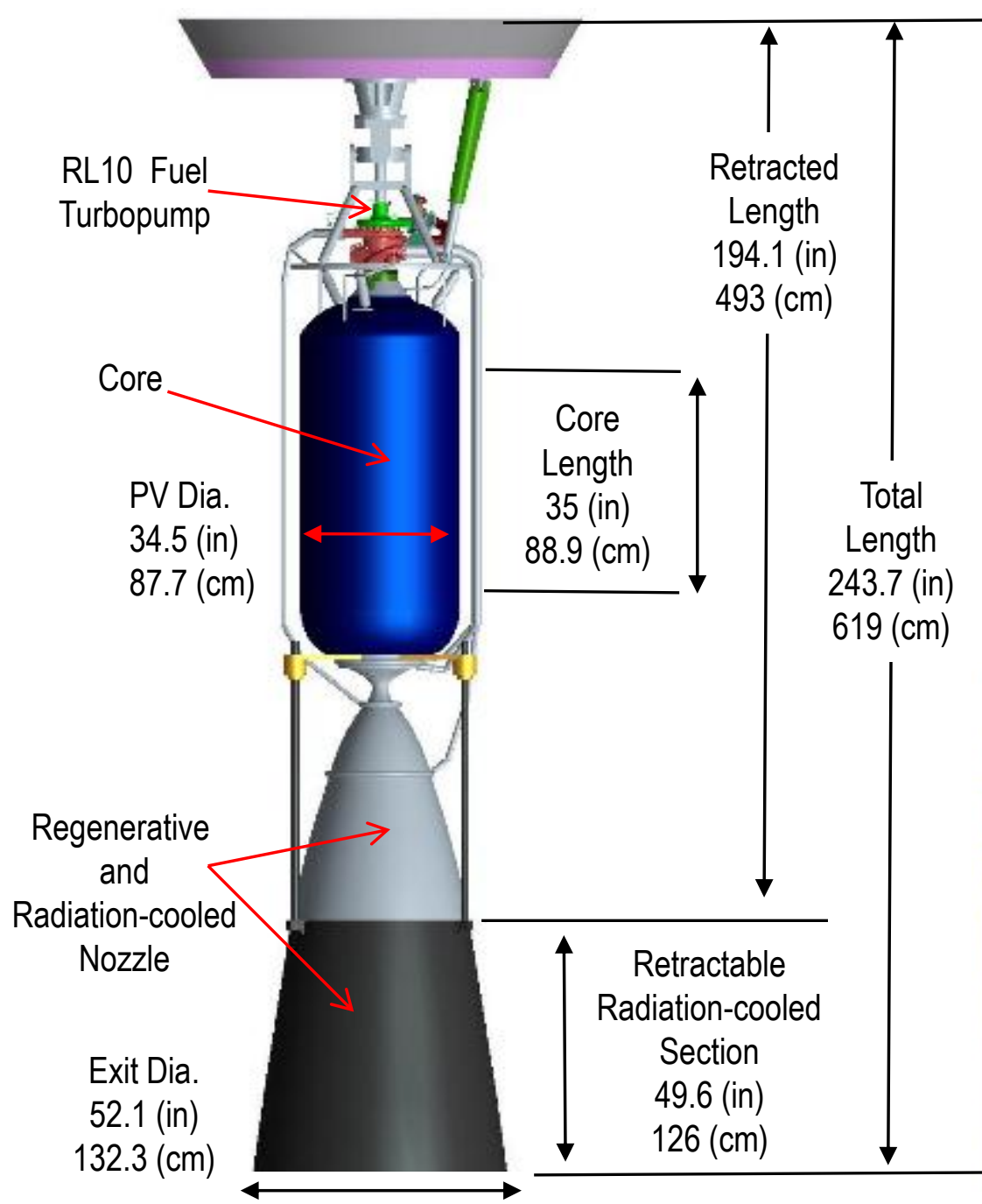

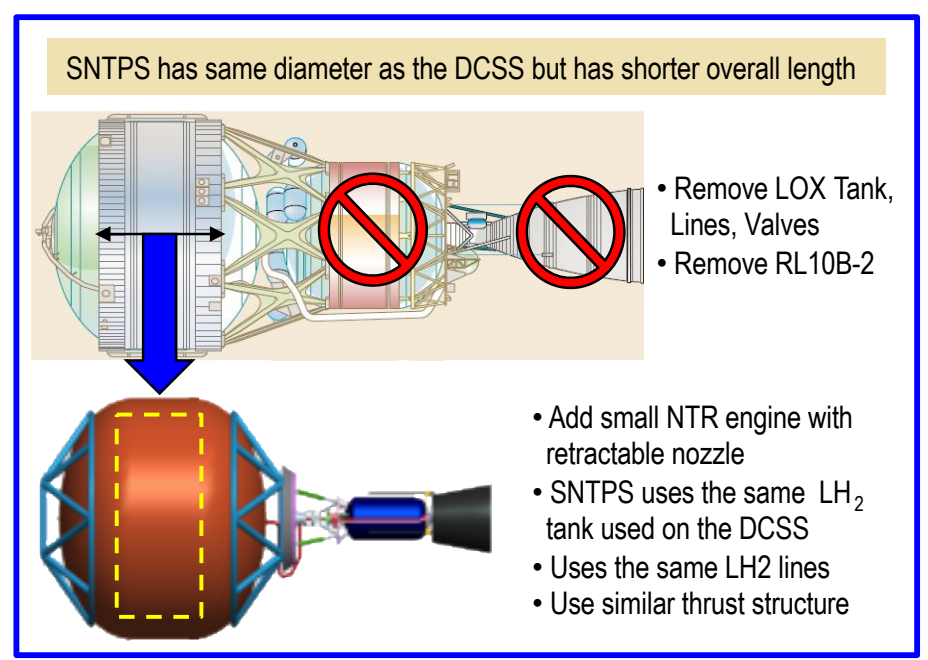

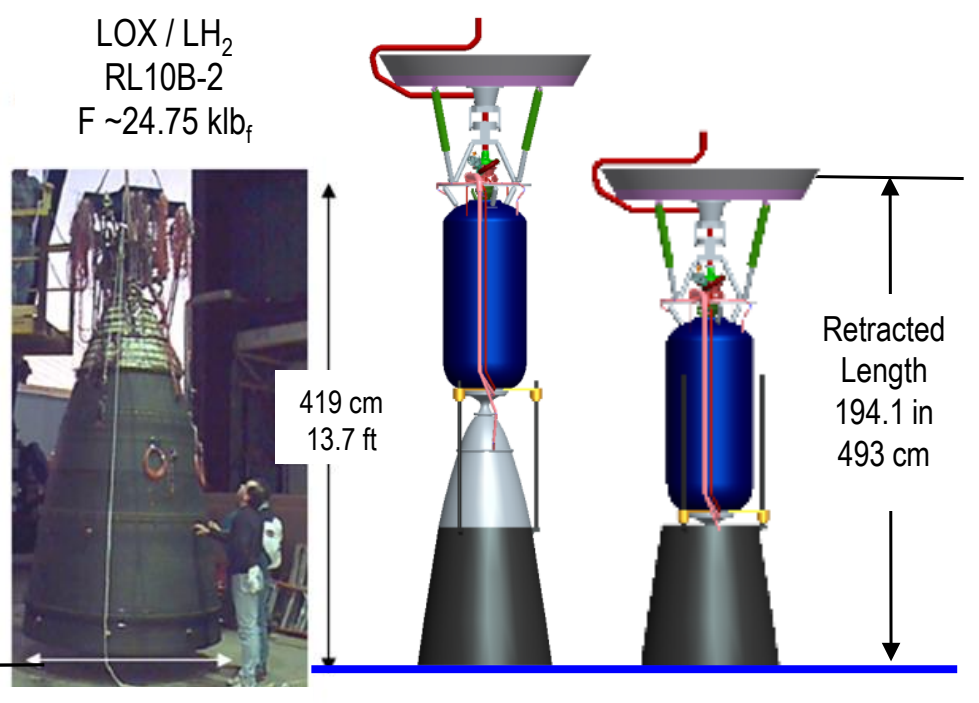

$211 \mathrm{~cm} / 6.9 \mathrm{ft}$ 


\section{Small NTPS FTD Mission: “Single-Burn Lunar Flyby"}
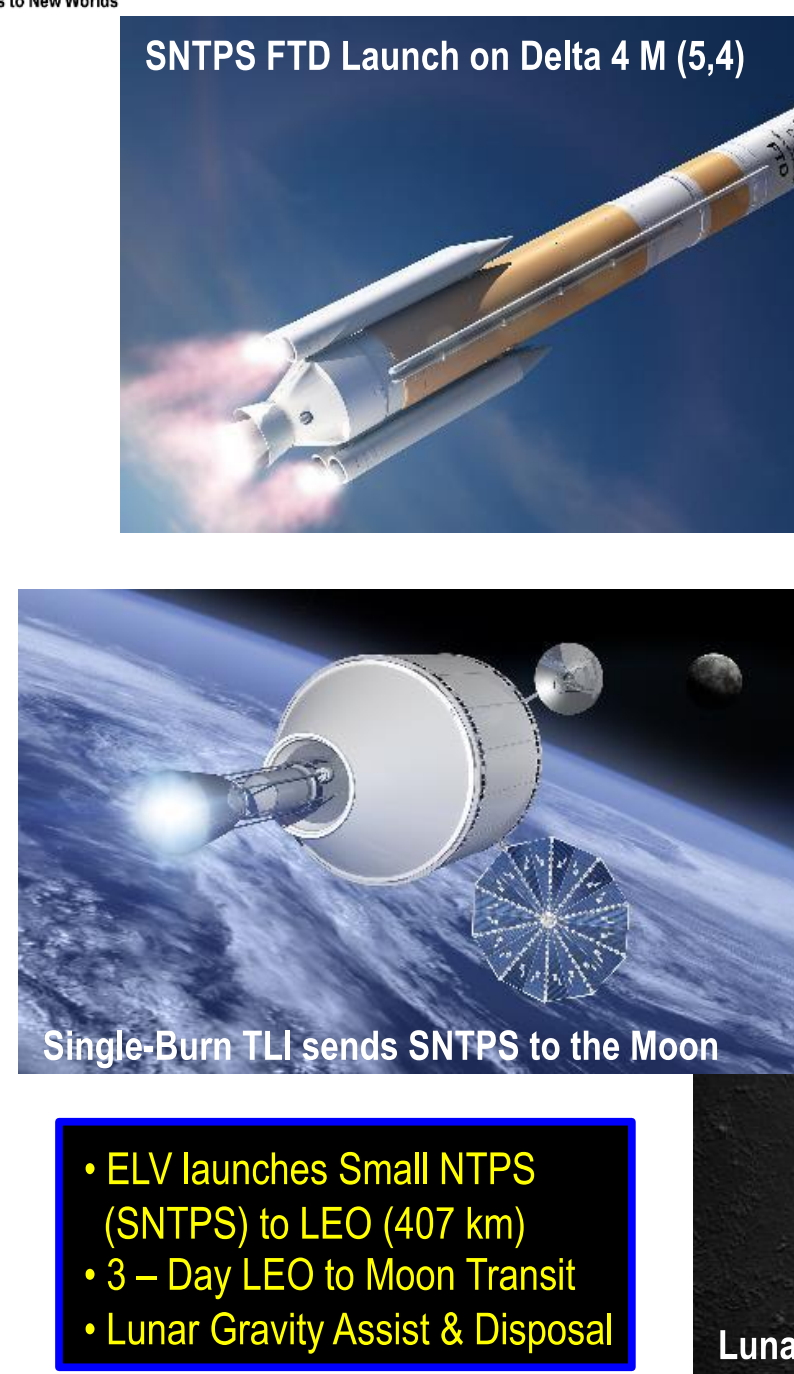

2.
- IMLEO 9.90 t

- $F \sim 7.52 \mathrm{klb}_{\mathrm{f}}$, Isp $\sim 894 \mathrm{~s}, \mathrm{~F} / \mathrm{W}_{\text {eng }} \sim 1.91$

- Dry Stage / $\mathrm{LH}_{2} / \mathrm{PL}$ mass $~ 6.42 \mathrm{t} 3.23 \mathrm{t} / 0.25 \mathrm{t}$

- $\Delta \mathrm{V}_{\mathrm{TLI}} /$ Burn time $\sim 3.16 \mathrm{~km} / \mathrm{s} / 12.97 \mathrm{mins}$

Earthrise Final Farewell Pictures

解
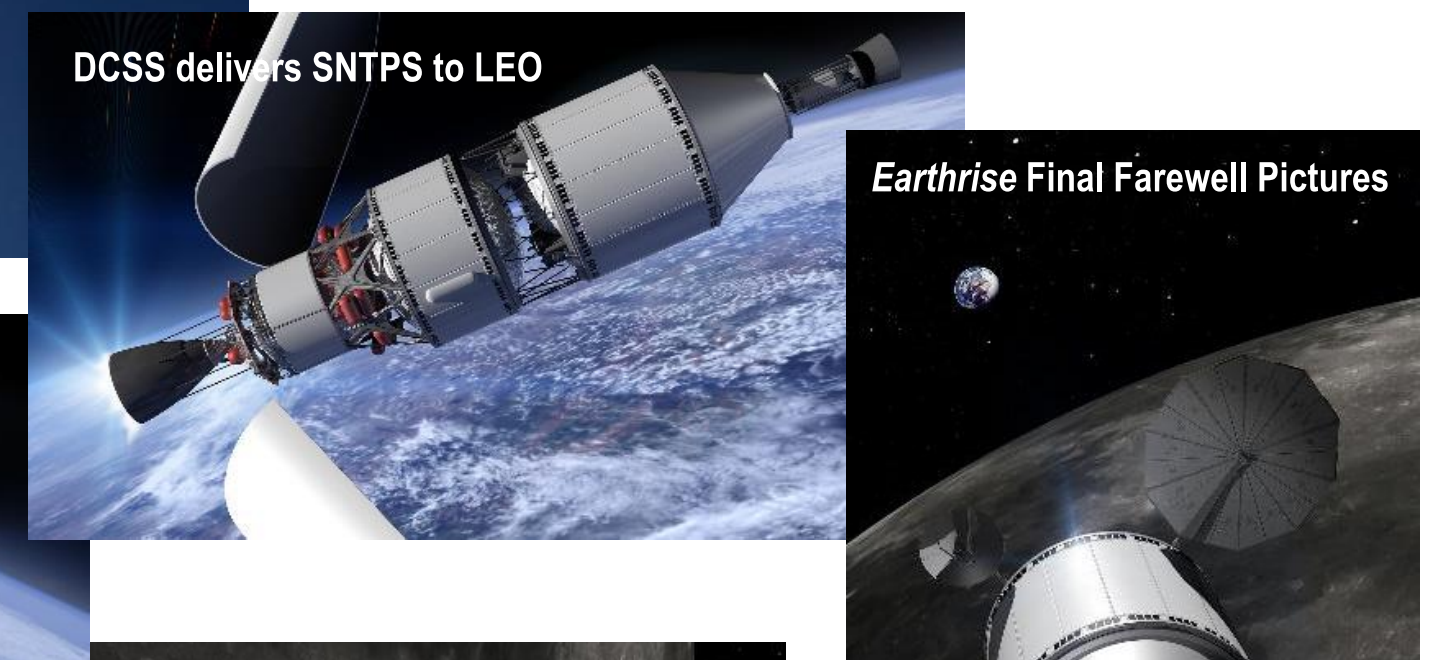

Lunar Gravity Assist sends SNTPS into Deep Space

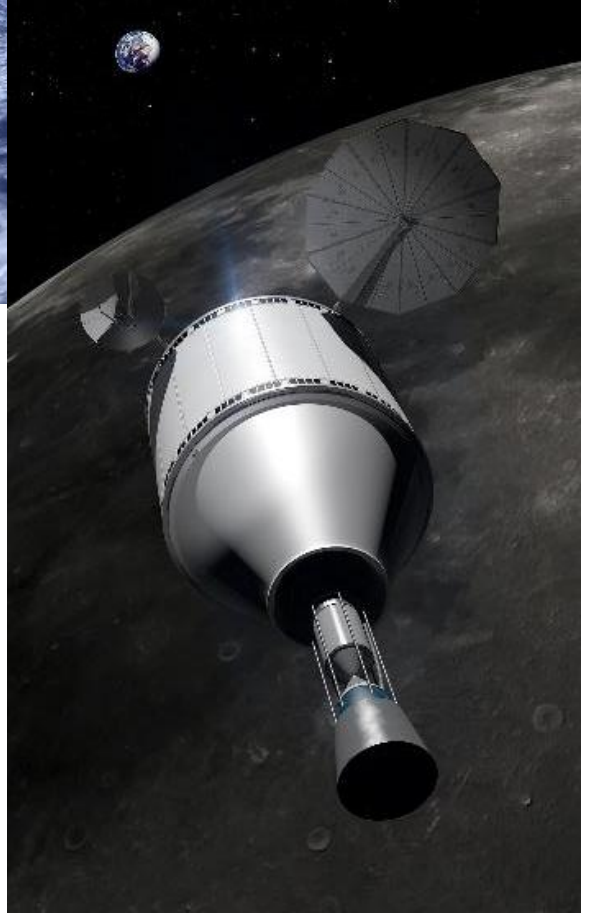




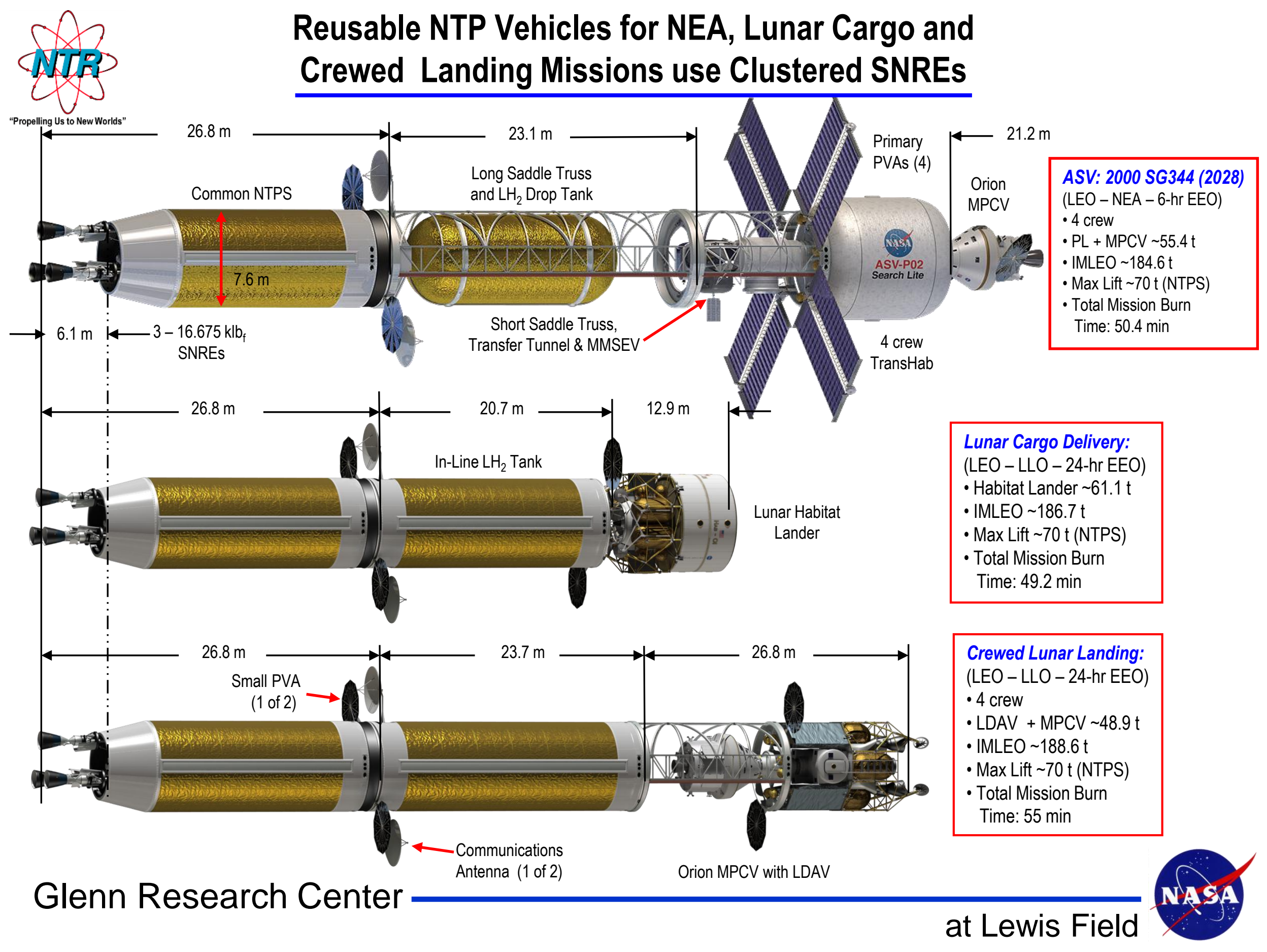




\section{Reusable NTP MSVN for NASA's EMC Carries 4 Crew and Uses SEP-delivered $\mathrm{LH}_{2}$ Propellant for Earth Return}

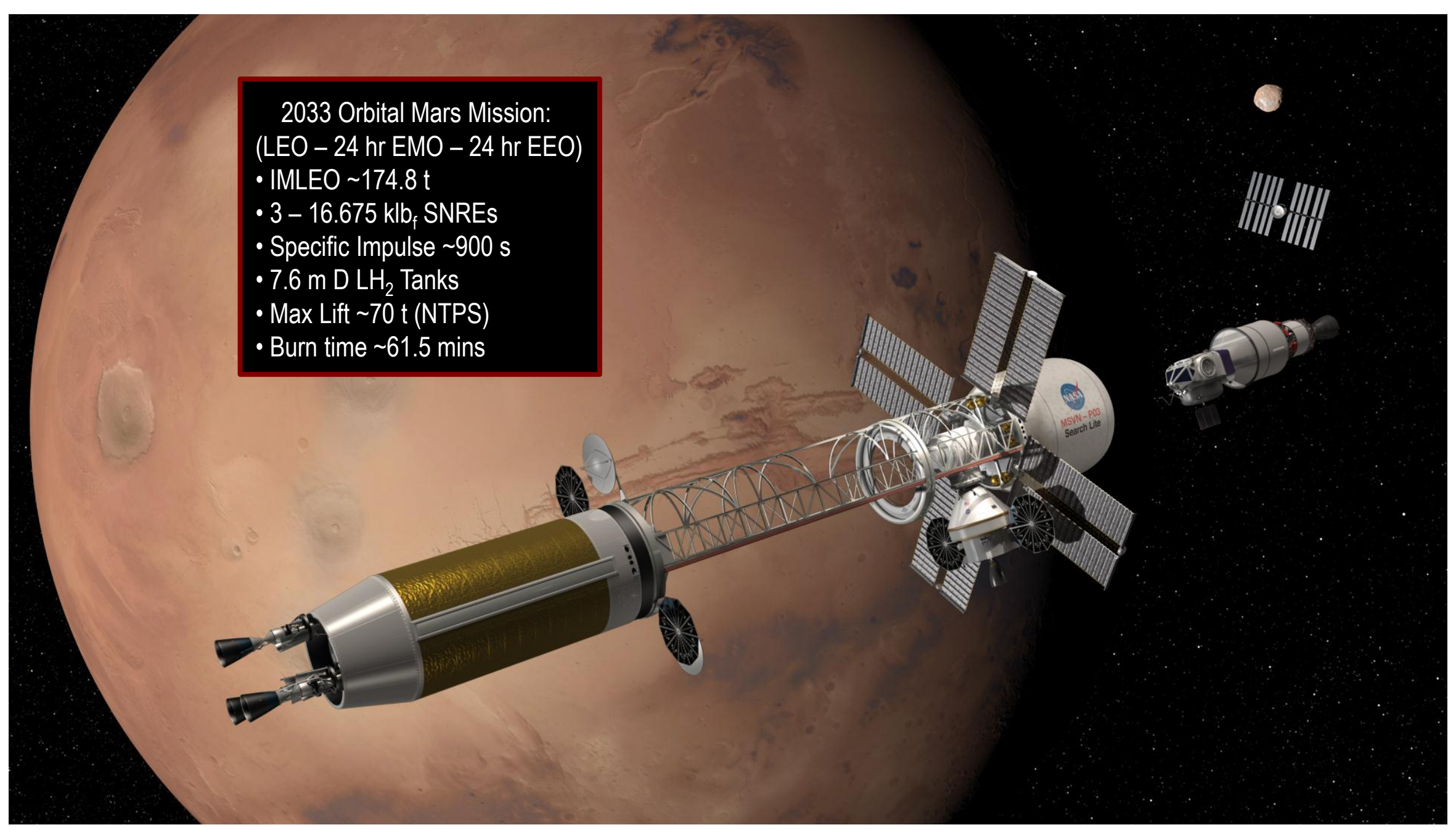




\section{Performance Requirements for Small GC NTRs for FTD, Lunar, NEA and Mars Exploration Missions}

\begin{tabular}{|c|c|c|c|c|c|c|c|c|c|c|}
\hline Requirements & $\begin{array}{c}\text { Engine } \\
\text { Thrust } \\
\left(\text { klb }_{\mathrm{f}}\right)\end{array}$ & $\mathbf{T} / \mathbf{W}_{\text {eng }}$ & $\begin{array}{l}\mathbf{T}_{\mathrm{ex}} \\
\left({ }^{\circ} \mathbf{K}\right)\end{array}$ & $\begin{array}{l}I_{\text {sp }} \\
(s)\end{array}$ & $\begin{array}{c}\text { No. } \\
\text { Engines }\end{array}$ & $\begin{array}{c}\text { U-235 } \\
\text { Mass } \\
\text { (kg) }\end{array}$ & $\begin{array}{l}\text { No. } \\
\text { burns }\end{array}$ & $\begin{array}{c}\text { Longest } \\
\text { Single } \\
\text { burn (min) }\end{array}$ & $\begin{array}{c}\text { Total } \\
\text { burn time } \\
\text { (min) }\end{array}$ & $\begin{array}{c}\text { U-235 } \\
\text { Burnup } \\
(\%)\end{array}$ \\
\hline $\begin{array}{c}\text { Lunar Flyby FTD } \\
\text { Mission }\end{array}$ & $\sim 7.5$ & $\sim 1.9$ & 2739 & 894 & 1 & 27.5 & 1 & $\sim 13.0$ & - & $\sim 0.0062$ \\
\hline $\begin{array}{c}\text { Lunar Flyby FTD } \\
\text { Mission }\end{array}$ & $\sim 16.7$ & $\sim 3.1$ & 2733 & 900 & 1 & 59.6 & 1 & $\sim 6.7$ & - & $\sim 0.0035$ \\
\hline $\begin{array}{c}\text { Lunar Cargo } \\
\text { Delivery }\end{array}$ & $\sim 16.7$ & $\sim 3.1$ & 2733 & 900 & 3 & 59.6 & 5 & $\sim 21.4$ & $\sim 49.2$ & $\sim 0.025$ \\
\hline $\begin{array}{c}\text { Lunar Landing } \\
\text { Crewed }\end{array}$ & $\sim 16.7$ & $\sim 3.1$ & 2733 & 900 & 3 & 59.6 & 5 & $\sim 21.0$ & $\sim 55.0$ & $\sim 0.028$ \\
\hline $\begin{array}{c}\text { NEA } 2000 \text { SG344 } \\
\text { Crewed }\end{array}$ & $\sim 16.7$ & $\sim 3.1$ & 2733 & 900 & 3 & 59.6 & 5 & $\sim 27.4$ & $\sim 50.4$ & $\sim 0.026$ \\
\hline EMC Crewed & $\sim 16.7$ & $\sim 3.1$ & 2733 & 900 & 3 & 59.6 & 5 & $\sim 24.2$ & $\sim 61.5$ & $\sim 0.032$ \\
\hline
\end{tabular}

- Both engines assume a peak fuel temperature of $2860 \mathrm{~K}$ and have a fuel loading of $\sim 0.6$ grams of $\mathrm{HEU}$ per $\mathrm{cm}^{3}$

The SNRE' option is recommended for development and testing. It can be used for the single engine FTD mission, and with clustered engines can support reusable lunar cargo delivery, crewed landing, and NEA survey missions. Even human missions to Mars are possible with reduced crew size and prepositioning of assets as currently being envisioned in NASA' s EMC study. 


\section{Assumptions for “Sporty" SNTPS GTD \& FTD Mission Schedule}

- A 10-year period to a ground tested "qualification engine" by 2024 is conceivable but challenging and many things must line up / flow well.

- By necessity it would be a success-oriented high-risk activity requiring immediate and serious financial commitments to the following areas:

- Management and acquisition approach is streamlined

- Composite fuel is the baseline and fuel element (FE) production levels are scaled up prior to complete verification of all processing activities; Testing conducted in bore holes at NTS

- NEPA and launch safety analyses is initiated along with ID' ed shipping and ATLO facility mods

- A single "portable hot cell unit" would be co-located near the site of the candidate borehole / tunnel. The unit would be a "turnkey" procurement and used to disassemble the reactor after testing to extract a sampling of FEs and reactor components for shipment to INL for PIE. The unit would be similar to that used by the UK at their Sellafield hot cell facility or the mobile SHARS unit developed by the IAEA. Afterwards the unit would be used to disassemble the reactor into smaller groupings of parts that would be shipped off-site for final disposal in "existing" shipping casks.

-The GTD program would focus on borehole testing of two units:

- Engineering reactor and engine test article (90\% fidelity) in 2023

- Qualification engine (100\% fidelity) in 2024 after qual-level testing (e.g., vibration) in 2023;

- The flight unit - identical to the qualification unit - would be launched in 2025 


\section{Notional NTP Ground \& Flight Test Demonstration Milestone Schedule}

"Propelling Us to New Worlds"

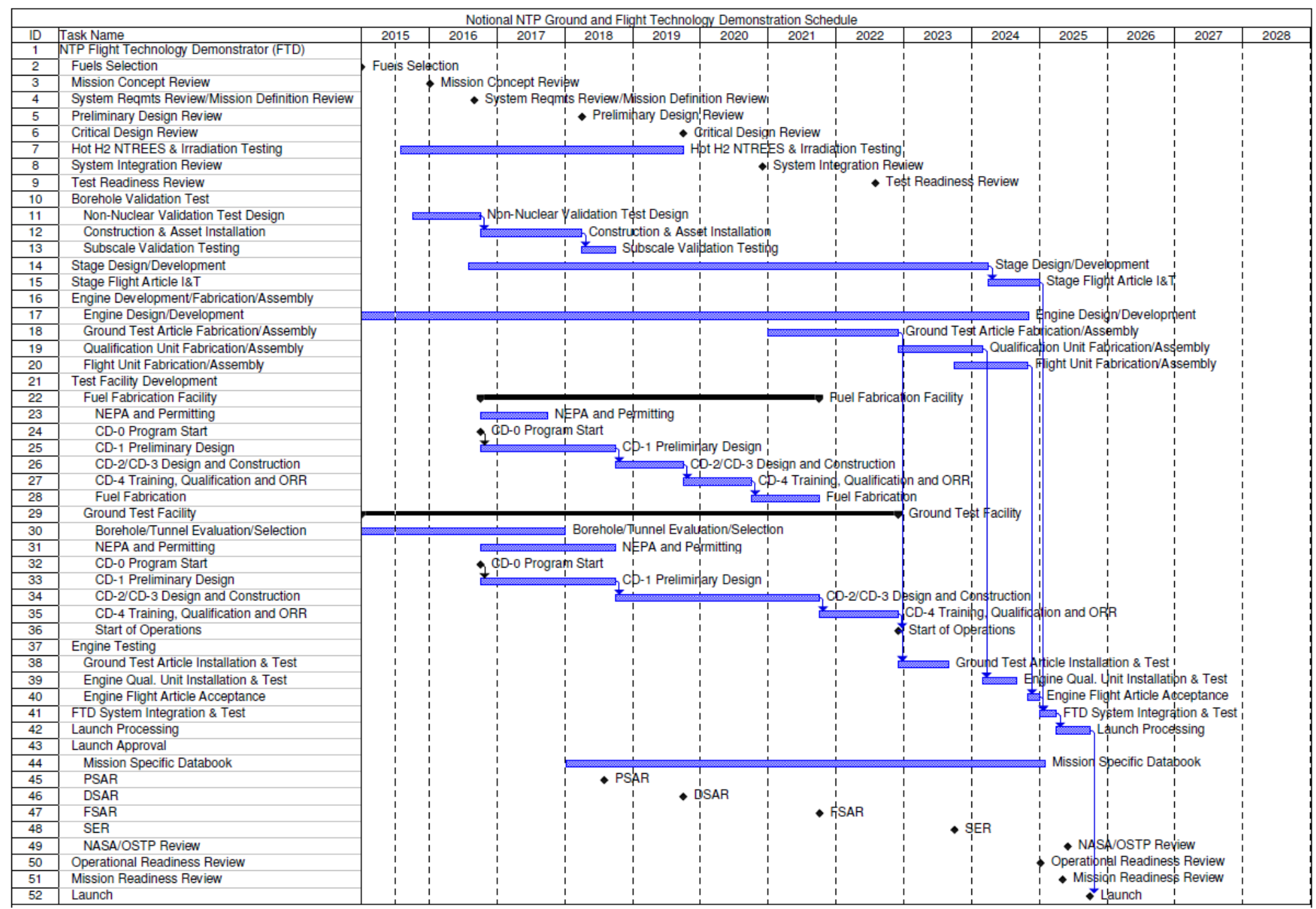




\section{Summary and Conclusions}

- In FY14, NASA and DOE (NE-75, ORNL, INL), with input from industry, formulated a preliminary development plan for the AES program for testing a small GTD $\left(\sim 7.5-16.5 \mathrm{klb}_{f}\right)$ engine in the early 2020 's followed by a FTD mission of a small NTP stage around 2025

- 10-years to a FTD mission in 2025 will require an immediate start and a serious and sustained financial commitment along with a streamlined management and acquisition approach - DOE

- Graphite-based "composite fuel" is the baseline; an engine using this fuel type can be built sooner than one using another less established / less tested fuel at relevant conditions - DOE

- Testing should be conducted at the NNSS using existing boreholes or tunnels and should maximize the use of existing facilities; consider new temporary / mobile facilities only as required; new nuclear infrastructure is a long lead item - DOE

- The FTD mission proposed is a 1-burn "lunar flyby" using a single SNRE ${ }^{+}$engine chosen to keep things simple and more affordable; clustered SNREs can support a full range of human exploration missions allowing a "one size fits all" approach to NTR development - GRC

- The keys to affordability include using: (1) proven "Graphite Composite" fuel; (2) "separate effects" testing (NTREES and irradiation) to qualify the fuel; (3) SOTA numerical models to design, build and operate the engine; (4) small engine design with a "common" FE that is scalable to larger sizes, when and if required; (5) existing DOE facilities at the NNSS (e.g., DAF, boreholes or tunnels); and (6) flight-proven, non-nuclear engine \& stage hardware to maximum extent possible for the FTD mission 